\title{
Design and synthesis of propellane derivatives and oxa-bowls via ring-rearrangement metathesis as a key step
}

\author{
Sambasivarao Kotha ${ }^{*} \S$ and Rama Gunta
}

\author{
Full Research Paper \\ Address: \\ Department of Chemistry, Indian Institute of Technology-Bombay, \\ Powai, Mumbai-400 076, India \\ Email: \\ Sambasivarao Kotha* - srk@chem.iitb.ac.in \\ * Corresponding author \\ $\S$ Fax: 022-25767152 \\ Keywords: \\ allylation; propellane derivatives; quinones; ring-rearrangement \\ metathesis
}

\author{
Beilstein J. Org. Chem. 2015, 11, 1727-1731. \\ doi:10.3762/bjoc.11.188 \\ Received: 15 June 2015 \\ Accepted: 10 September 2015 \\ Published: 24 September 2015 \\ This article is part of the Thematic Series "Progress in metathesis \\ chemistry II". \\ Guest Editor: K. Grela \\ (c) 2015 Kotha and Gunta; licensee Beilstein-Institut. \\ License and terms: see end of document.
}

Open Access

\begin{abstract}
Various intricate propellane derivatives and oxa-bowls have been synthesized via a ring-rearrangement metathesis (RRM) as a key step starting from readily accessible starting materials such as $p$-benzoquinone, 1,4-naphthoquinone and 1,4-anthraquinone.
\end{abstract}

\section{Introduction}

The synthesis of complex target structures requires bonddisconnection analysis of the target molecule, eventually to arrive at simple starting materials by working in an opposite direction to a chemical synthesis. The 'retrosynthetic analysis' was first introduced by E. J. Corey and defined as "it is a problem solving technique for transforming the structure of a synthetic target molecule to a sequence of progressively simpler structures along a pathway which ultimately leads to a simple or commercially available starting materials for a chemical synthesis" [1] . Generally, this type of retrosynthetic analysis has been used to design [2-6] the target molecule. However, a "transformation-based" retrosynthetic approach is rarely used. In the transformation-based strategy the target and precursor compounds are related by a rearrangement as the key transformation. The advantages of the rearrangement-based strategy are: the target molecule can be assembled from less obvious and more accessible precursors. Several $\mathrm{C}-\mathrm{C}$ bonds are formed in a simple manner by taking advantage of the key rearrangement and the overall synthetic economy of the process can be enhanced. One can design unprecedented synthetic routes to complex targets [7] through the rearrangement-based approach. In this regard, the ring-rearrangement metathesis (RRM) [8-12] is useful and moreover, the stereochemical information can be transferred from the starting material to the final product during the RRM. In continuation of our interest to design novel molecules via metathesis [13-20] we conceived a new and simple route to propellane derivatives and oxa-bowls [21-26]. This strategy starts from simple starting materials and involves a Diels-Alder (DA) reaction [27,28] and RRM as the key steps. 


\section{Results and Discussion}

\section{Strategy}

The retrosynthetic strategy to diverse propellane derivatives and oxa-bowls is shown in Figure 1. Oxa-bowl $\mathbf{1}$ can be synthesized from the tetracyclic compound $\mathbf{2}$ using RRM, which could be obtained from the known DA adduct 3 by O-allylation. On the other hand, the propellane derivative 7 may be synthesized from the tetraallyl compound $\mathbf{6}$ by a RRM sequence. Further, the tetraallyl compound $\mathbf{6}$ can be assembled from the C-allyl derivative 4 via reduction followed by O-allylation. The C-allyl derivative $\mathbf{4}$ may be obtained from the known DA adduct 3 by a $\mathrm{C}$-allylation sequence which in turn could be prepared by the DA reaction of the corresponding 1,4-quinones ( $p$-benzoquinone, 1,4-naphthoquinone or 1,4-anthraquinone) with a freshly cracked cyclopentadiene.

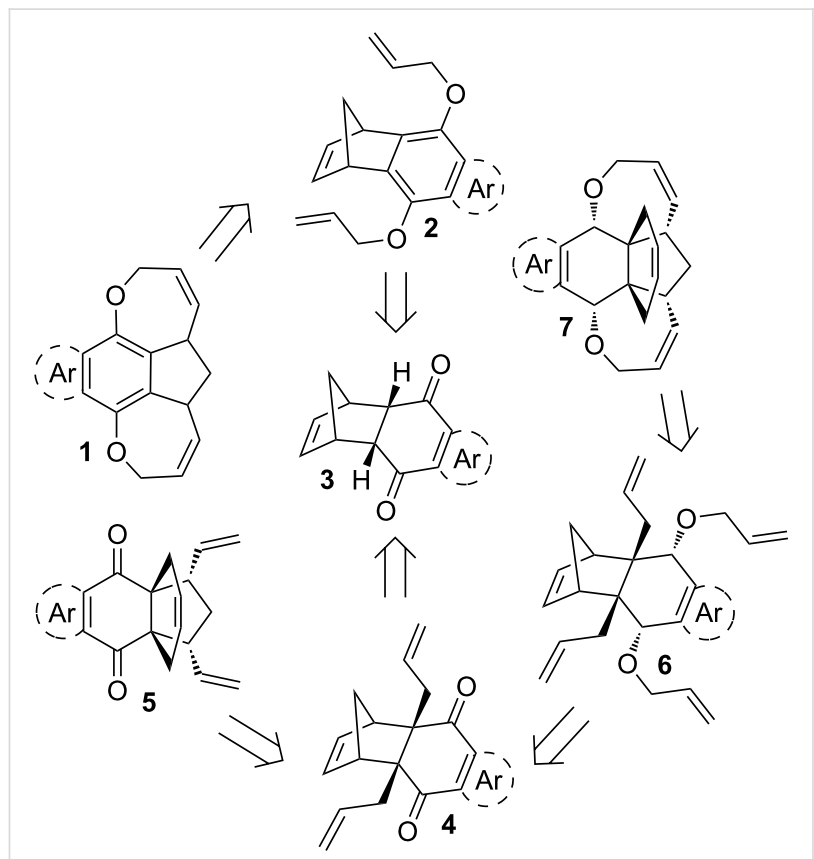

Figure 1: RRM route to propellane derivatives and oxa-bowls.

To realize the synthetic strategy (Figure 1) to various propellane derivatives [29-31] and oxa-bowls, we commenced with the preparation of a known DA adduct 3a [32]. Subsequent ally- lation of 3a with allyl bromide in the presence of $\mathrm{NaH}$ delivered the aromatized compound $\mathbf{2 a}$ in $42 \%$ yield. Then, the tricyclic compound 2a was subjected to RRM with Grubbs $1^{\text {st }}$ generation (G-I) catalyst in the presence of ethylene to furnish the tetracyclic compound $1 \mathbf{a}$ in $75 \%$ yield (Scheme 1). The structures of compounds $2 \mathrm{a}$ and $\mathbf{1 a}$ have been confirmed on the basis of ${ }^{1} \mathrm{H},{ }^{13} \mathrm{C}$ NMR and DEPT-135 spectral data and further supported by HRMS data.

To expand the strategy, another DA adduct $\mathbf{3 b}$ was prepared from the commercially available 1,4-naphthoquinone and freshly cracked cyclopentadiene by following the literature procedure [33]. Allylation of adduct $\mathbf{3 b}$ under similar reaction conditions as described above gave O-allylated compound $\mathbf{2 b}$ and C-allylated compound $\mathbf{4 a}$ in $70 \%$ and $28 \%$ yields, respectively. Then, treatment of the O-allyl compound $\mathbf{2 b}$ with G-I catalyst in the presence of ethylene at room temperature (rt) produced the RRM product, a pentacyclic oxa-bowl $\mathbf{1 b}$ in $90 \%$ yield. When the C-allyl compound $\mathbf{4 a}$ was treated with G-II catalyst in $\mathrm{CH}_{2} \mathrm{Cl}_{2}$ at $\mathrm{rt}$ or in refluxing toluene, the propellane derivative 5 a was obtained in $69 \%$ yield (Scheme 2 ). The structures of the new compounds $\mathbf{2 b}, \mathbf{4 a}, \mathbf{1 b}$ and $\mathbf{5 a}$ have been established on the basis of ${ }^{1} \mathrm{H}$ and ${ }^{13} \mathrm{C}$ NMR spectral data and further supported by HRMS data.

Next, another DA adduct 3c was prepared from readily available starting materials. In this regard, 1,4-anthraquinone was prepared from quinizarin (1,4-dihydroxyanthraquinone) by using the literature procedure [34] and the known DA adduct 3c was obtained by a cycloaddition reaction [35] of 1,4anthraquinone and cyclopentadiene.

Again, allylation of the DA adduct $\mathbf{3 c}$ with allyl bromide in the presence of $\mathrm{NaH}$ afforded the O-allylated compound $2 \mathrm{c}$ in $41 \%$ and the $\mathrm{C}$-allylated compound $\mathbf{4 b}$ in $\mathbf{7 \%}$ yield. Compound $\mathbf{2 c}$ was further subjected to RRM with G-I catalyst in the presence of ethylene to deliver the hexacyclic oxa-bowl 1c in quantitative yield (Scheme 3).

Having the C-allylated DA adducts $\mathbf{4 a}, \mathbf{b}$ in hand, compound $\mathbf{4 a}$ was reduced with diisobutylaluminium hydride (DIBAL-H) at

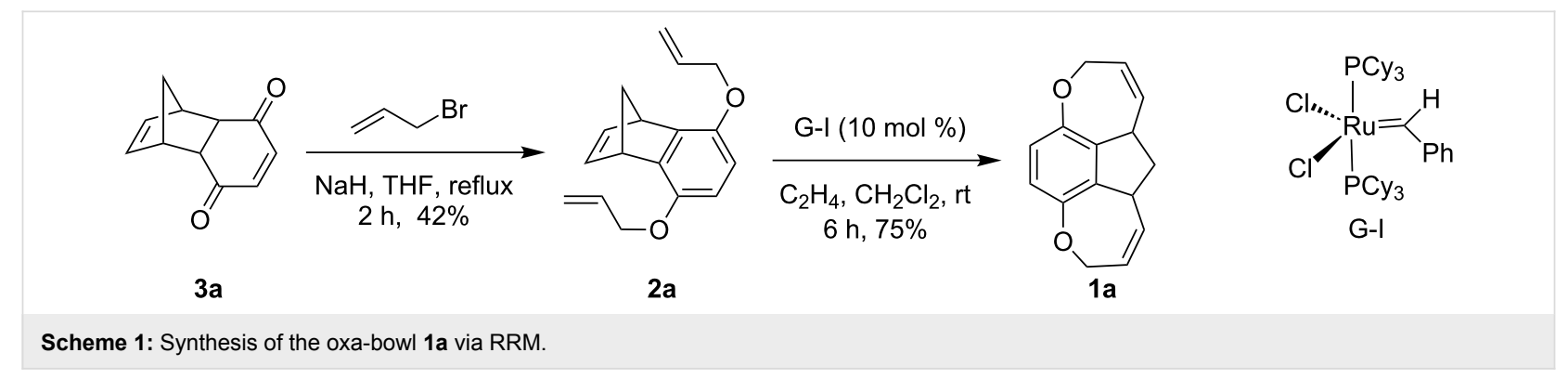




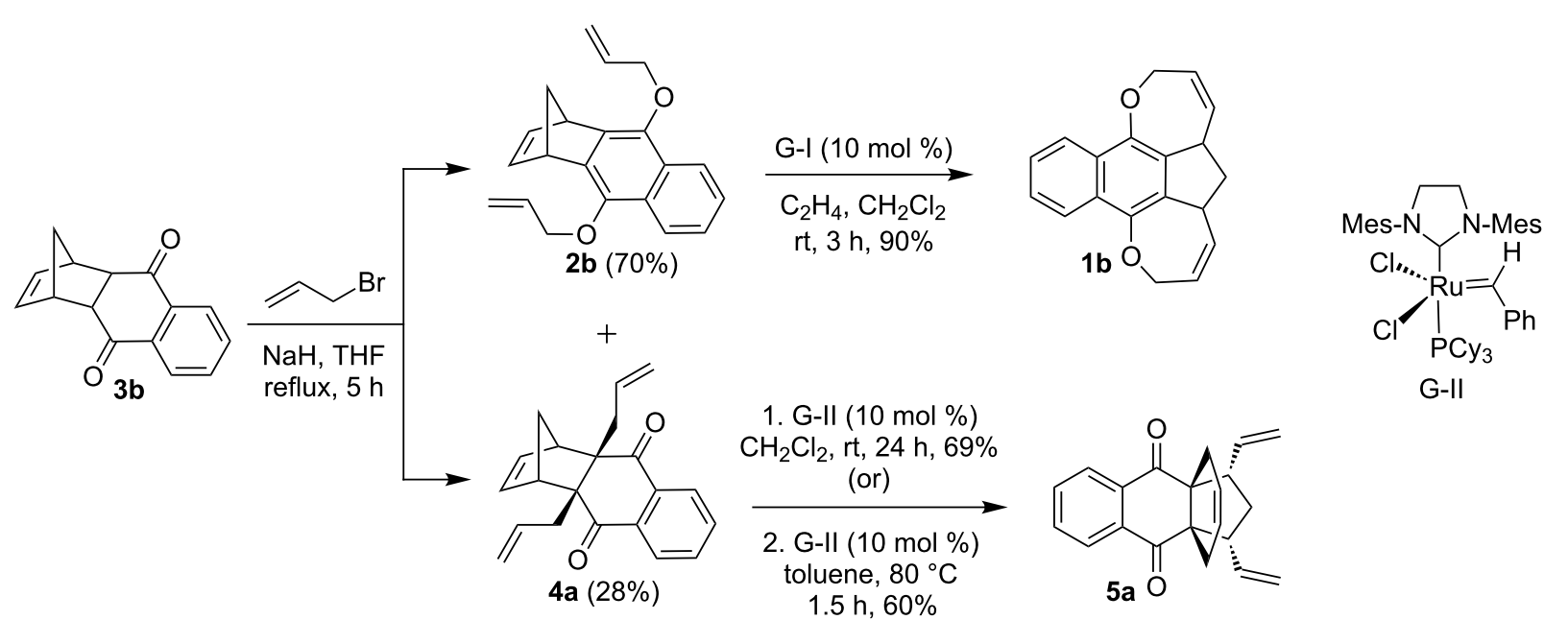

Scheme 2: Synthesis of RRM products $\mathbf{1 b}$ and $\mathbf{5 a}$ starting from DA adduct $\mathbf{3 b}$.
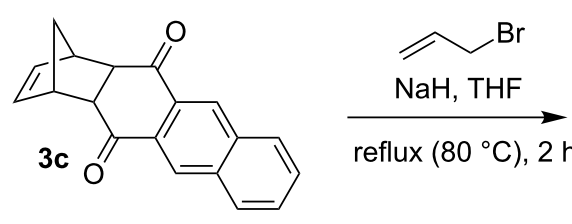
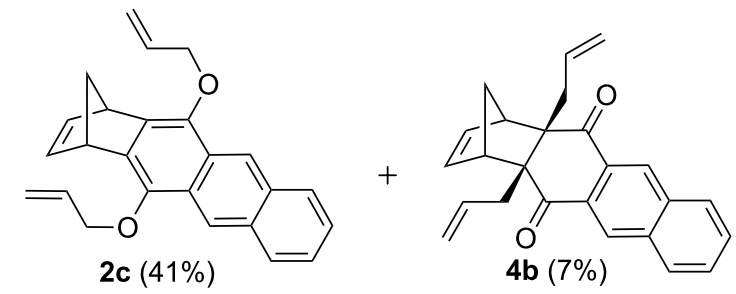

G-I (10 mol \%), $\mathrm{C}_{2} \mathrm{H}_{4}$<smiles>C1=CC2Cc3ccccc3CC2C=COC1</smiles>

Scheme 3: Synthesis of the hexacyclic compound 1c using RRM.

$-74{ }^{\circ} \mathrm{C}$ to furnish diol $8 \mathrm{a}$ in $81 \%$ yield along with a minor amount of compound $9(8 \%)$. The formation of compound 9 may be explained on the basis of a retro-DA reaction [36] followed by reduction and elimination. In the same way, reduction of C-allyl compound $\mathbf{4 b}$ under similar reaction conditions gave diol $\mathbf{8 b}$ in $88 \%$ yield.

In the next step, diols $\mathbf{8 a}, \mathbf{b}$ were O-allylated with allyl bromide in the presence of $\mathrm{NaH}$ to furnish the desired RRM precursors $\mathbf{6 a}, \mathbf{b}$ in $67 \%$ and $79 \%$ yields respectively (Scheme 4 ).

Finally, the tetraallyl derivatives $\mathbf{6 a}, \mathbf{b}$ were subjected to RRM with G-I catalyst in the presence of ethylene at $\mathrm{rt}$ to produce the corresponding propellane/oxa-bowl hybrids $7 \mathbf{a}, \mathbf{b}$ in $71 \%$ and
97\% yields, respectively. The new compounds $\mathbf{2 c}, \mathbf{4 b}, \mathbf{1 c}, \mathbf{8 a}, \mathbf{b}$, $\mathbf{9}, \mathbf{6 a}, \mathbf{b}$ and $7 \mathbf{a}, \mathbf{b}$ have been fully characterized by using spectroscopic techniques $\left({ }^{1} \mathrm{H},{ }^{13} \mathrm{C}\right.$ NMR and DEPT-135) and HRMS data.

\section{Conclusion}

We have successfully synthesized diverse heterocycles $\mathbf{1 a - c}$ in a simple manner starting from the known DA adducts $\mathbf{3 a - c}$, including the propellane/oxa-bowl hybrids $7 \mathbf{a}, \mathbf{b}$ and propellane derivative 5a. Interestingly, the structurally complex propellane/ oxa-bowl hybrids $\mathbf{7 a}, \mathbf{b}$ were obtained through a four step synthetic sequence starting from simple DA adducts $\mathbf{3 b}$,c, which are otherwise difficult to synthesize following conventional retrosynthetic routes. This methodology can easily be extended 


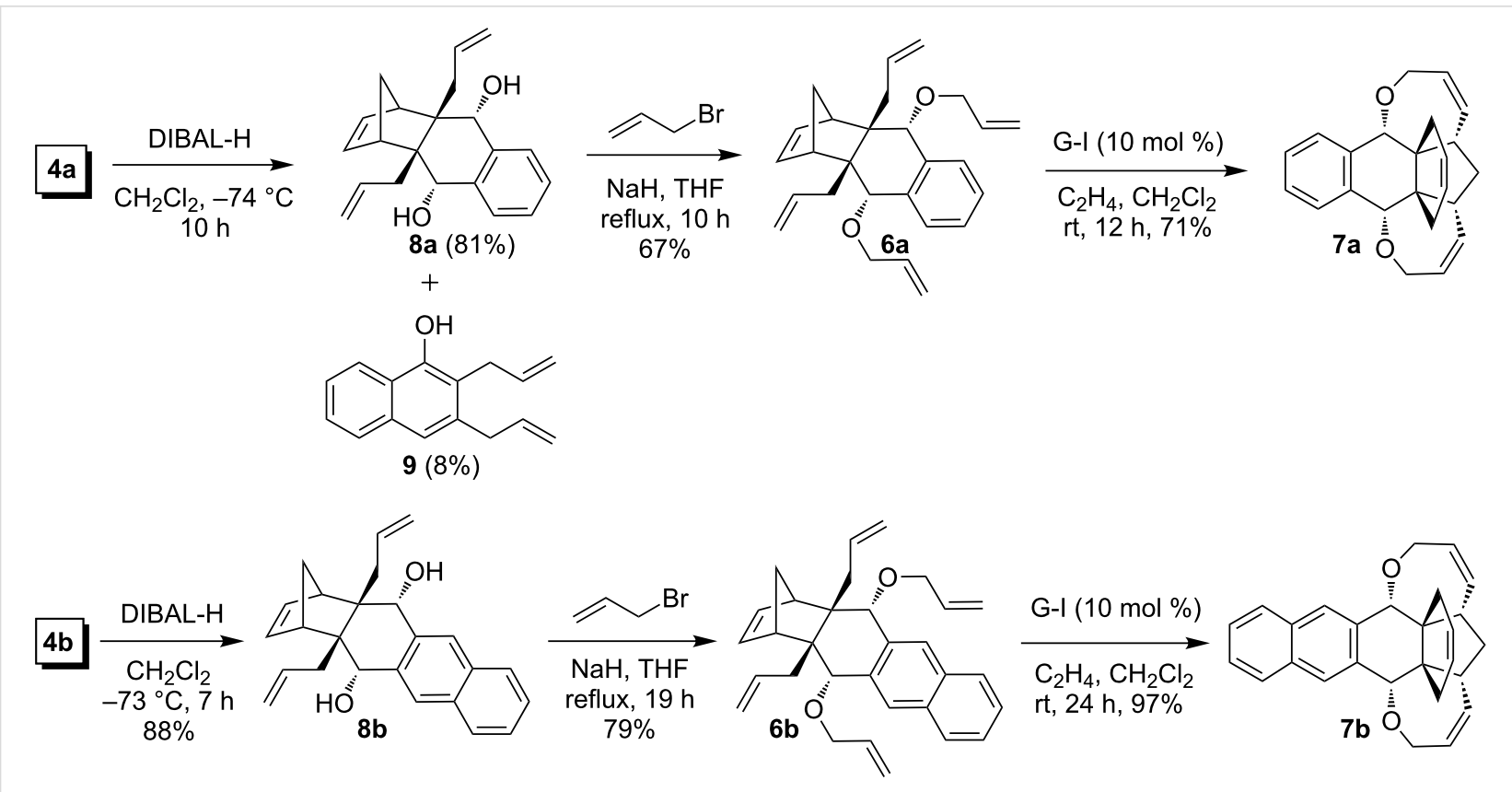

Scheme 4: Synthesis of the propellane/oxa-bowl hybrids $7 a, b$ via RRM.

for diversity-oriented synthesis [37] by employing different dienes and dienophiles during the DA reaction sequence.

\section{Supporting Information}

\section{Supporting Information File 1}

Detailed experimental procedures, characterization data and copies of ${ }^{1} \mathrm{H}$ and ${ }^{13} \mathrm{C}$ NMR for all new compounds. [http://www.beilstein-journals.org/bjoc/content/ supplementary/1860-5397-11-188-S1.pdf]

\section{Acknowledgements}

We thank the Department of Science and Technology (DST), New Delhi for the financial support and the Sophisticated Analytical Instrument Facility (SAIF), IIT-Bombay for recording spectral data. S.K. thanks the Department of Science and Technology for the award of a J. C. Bose fellowship. R.G. thanks the University Grants Commission (UGC), New Delhi for the award of a research fellowship.

\section{References}

1. Corey, E. J.; Cheng, X.-M. The Logic of Chemical Synthesis; John Wiley \& Sons: New York, 1989.

2. Hanessian, S.; Giroux, S.; Merner, B. L. Design and Strategy in Organic Synthesis; Wiley-VCH: Weinheim, 2013.

3. Wyatt, P.; Warren, S. Organic Synthesis: Strategy and Control; John Wiley \& Sons: Sussex, 2013.
4. Smit, W. A.; Bochkov, A. F.; Caple, R. Organic Synthesis: The Science Behind the Art; Royal Society of Chemistry: Cambridge, 1998. doi:10.1039/9781847551573

5. Hopf, H. Classics in Hydrocarbon Chemistry; Wiley-VCH: Weinheim, 2000.

6. Hudlicky, T.; Reed, J. W. The Way of Synthesis: Evolution of Design and Methods for Natural Products; Wiley-VCH: Weinheim, 2007.

7. Nicolaou, K. C.; Sorensen, E. J. Classics in Total Synthesis: Targets, Strategies, Methods; Wiley-VCH: Weinheim, 1996.

8. Holub, N.; Blechert, S. Chem. - Asian J. 2007, 2, 1064-1082. doi:10.1002/asia.200700072 And references cited therein.

9. Schmidt, B.; Krehl, S. Domino and Other Olefin Metathesis Reaction Sequences. In Olefin Metathesis: Theory and Practice, Part I; Grela, K., Ed.; John Wiley \& Sons: Hoboken, New Jersey, 2014.

10. Nolan, S. P.; Clavier, H. Chem. Soc. Rev. 2010, 39, 3305-3316. doi:10.1039/B912410c

11. Kotha, S.; Ravikumar, O. Eur. J. Org. Chem. 2014, 5582-5590. doi:10.1002/ejoc.201402273

12. Kotha, S.; Gunta, R. Beilstein J. Org. Chem. 2015, 11, 1373-1378. doi:10.3762/bjoc.11.148

13. Grubbs, R. H.; O'Leary, D. J., Eds. Handbook of Metathesis, 2nd ed.; Wiley-VCH: Weinheim, 2015; Vol. 2.

14. Kotha, S.; Misra, S.; Sreevani, G.; Babu, B. V. Curr. Org. Chem. 2013, 17, 2776-2795. doi:10.2174/13852728113179990118

15. Kotha, S.; Dipak, M. K. Tetrahedron 2012, 68, 397-421. doi:10.1016/j.tet.2011.10.018

16. Kotha, S.; Krishna, N. G.; Halder, S.; Misra, S. Org. Biomol. Chem. 2011, 9, 5597-5624. doi:10.1039/c1ob05413a

17. Kotha, S.; Meshram, M.; Tiwari, A. Chem. Soc. Rev. 2009, 38 , 2065-2092. doi:10.1039/B810094m

18. Kotha, S.; Lahiri, K. Synlett 2007, 2767-2784. doi:10.1055/s-2007-990954 
19. Kotha, S.; Sreenivasachary, N. Indian J. Chem., Sect. B 2001, 40, 763-780.

20. Kotha, S.; Mandal, K. Tetrahedron Lett. 2004, 45, 1391-1394. doi:10.1016/j.tetlet.2003.12.075

21. Kotha, S.; Chinnam, A. K. Synthesis 2014, 46, 301-306. doi:10.1055/s-0033-1340341

22. Kotha, S.; Chinnam, A. K.; Tiwari, A. Beilstein J. Org. Chem. 2013, 9 , 2709-2714. doi:10.3762/bjoc.9.307

23. Kotha, S.; Chavan, A. S.; Dipak, M. K. Tetrahedron 2011, 67, 501-504. doi:10.1016/j.tet.2010.10.080

24. Kotha, S.; Dipak, M. K. Chem. - Eur. J. 2006, 12, 4446-4450. doi:10.1002/chem.200501366

25. Gharpure, S. J.; Porwal, S. K. Org. Prep. Proced. Int. 2013, 45, 81-153. doi:10.1080/00304948.2013.764782 And references cited therein.

26. Kotha, S.; Ravikumar, O. Tetrahedron Lett. 2014, 55, 5781-5784. doi:10.1016/j.tetlet.2014.08.108

27. Kotha, S.; Chavan, A. S.; Goyal, D. ACS Comb. Sci. 2015, 17, 253-302. doi:10.1021/co500146u

28. Kotha, S.; Brahmachary, E.; Sreenivasachary, N. Tetrahedron Lett. 1998, 39, 4095-4098. doi:10.1016/S0040-4039(98)00562-0

29. Ginsburg, D. Propellanes: Structure and Reactions; Verlag Chemie: Weinheim, 1975.

30. Ginsburg, D. Propellanes: Structure and Reactions: Sequel I; Technion: Haifa, 1981.

31. Ginsburg, D. Propellanes: Structure and Reactions: Sequel II; Technion: Haifa, 1985.

32. Mal, D.; Ray, S. Eur. J. Org. Chem. 2008, 3014-3020. doi:10.1002/ejoc.200800218

33. Valderrama, J. A.; Espinoza, O.; González, M. F.; Tapia, R. A.; Rodríguez, J. A.; Theoduloz, C.; Schmeda-Hirschmann, G. Tetrahedron 2006, 62, 2631-2638. doi:10.1016/j.tet.2005.12.038 And references cited therein.

34. Hua, D. H.; Tamura, M.; Huang, X.; Stephany, H. A.; Helfrich, B. A.; Perchellet, E. M.; Sperfslage, B. J.; Perchellet, J.-P.; Jiang, S.; Kyle, D. E.; Chiang, P. K. J. Org. Chem. 2002, 67, 2907-2912. doi:10.1021/jo010958s

35. Patney, H. K.; Paddon-Row, M. N. Synthesis 1986, 326-328. doi:10.1055/s-1986-31602

36. Kotha, S.; Banerjee, S. RSC Adv. 2013, 3, 7642-7666. doi:10.1039/C3ra22762f

37. Trabocchi, A. Diversity-Oriented Synthesis: Basics and Applications in Organic Synthesis, Drug Discovery, and Chemical Biology; John Wiley \& Sons: Hoboken, 2013

\section{License and Terms}

This is an Open Access article under the terms of the Creative Commons Attribution License

(http://creativecommons.org/licenses/by/2.0), which permits unrestricted use, distribution, and reproduction in any medium, provided the original work is properly cited.

The license is subject to the Beilstein Journal of Organic Chemistry terms and conditions:

(http://www.beilstein-journals.org/bjoc)

The definitive version of this article is the electronic one which can be found at:

doi:10.3762/bjoc. 11.188 